\title{
Humoral and cellular immune parameters before and during immunosuppressive therapy of a patient with stiff-man syndrome and insulin dependent diabetes mellitus
}

\author{
M Hummel, I Durinovic-Bello, E Bonifacio, V Lampasona, J Endl, S Fessele, \\ F Then Bergh, C Trenkwalder, E Standl, A-G Ziegler
}

\begin{abstract}
Objectives-Humoral and cellular immune reactivity are reported for two neuroendocrine autoantigens-glutamic acid decarboxylase (GAD) and the protein tyrosine phosphatase IA-2-in a patient with the autoimmune type of stiff-man syndrome and insulin dependent diabetes (IDDM).

Methods-Antibodies and $T$ cell proliferation against GAD and IA-2 and cytokine release of antigen stimulated $T$ cells (IFN- $\gamma$ ) were determined before and several times during immunosuppressive therapy with prednisolone.

Results-Raised GAD antibodies against full length GAD65 or chimeric constructs were detected before therapy and they remained at a high concentration despite a marked clinical improvement during cortisone treatment. Antibodies to IA-2 were undetectable, but weak $T$ cell responses to both GAD and IA-2 were seen before therapy and once on reduction of high cortisone dosages when the patient showed signs of clinical deterioration. Cytokine profiles showed increased IFN- $\gamma$ production after stimulation with GAD or IA-2 suggesting increased activation of $T_{H} 1$ cells.

Conclusion-Immunosuppressive therapy -even with extremely high doses of 500 mg a day-does not lead to the reduction of antibody concentrations in the periphery nor to a switch in epitope recognition of such antibodies despite clinical improvement. The amount of $T$ cell reactivity to various antigens, however, may be a useful marker to monitor the effectiveness of immunotherapy.

(F Neurol Neurosurg Psychiatry 1998;65:204-208)
\end{abstract}

Keywords: stiff-man syndrome; $\mathrm{T}$ cell reactivity; autoantibodies; prednisolone therapy

Correspondence to: Dr Anette-G Ziegler, Diabetes Research Institute, Kölner Platz 1, 80804 Munich, Germany.

Telephone 089-30 793121 ; fax 089-3 081733 ; email anziegler@1rz.

uni-muenchen.de

Received 23 September 1997 and in revised form

27 November 1997

Accepted

23 December 1997

Stiff-man syndrome is a rare disorder of the CNS, characterised by painful spasms and progressive symmetric rigidity of the axial and proximal muscles. ${ }^{1}$ Three different aetiological subtypes of stiff-man syndrome have been described: an autosomal dominant disorder with early onset in childhood called stiff-baby syndrome, ${ }^{2}$ stiff-man syndrome associated with breast cancer and characterised by autoanti- bodies to the $128 \mathrm{kDa}$ synaptic vesicle associated protein amphiphysin, ${ }^{34}$ and the most common autoimmune stiff-man syndrome $(60 \%)$ often associated with additional autoimmune diseases such as insulin dependent diabetes mellitus. ${ }^{56}$ The association of stiff-man syndrome and insulin dependent diabetes mellitus is, from an immunological point of view, extremely interesting, because the two diseases share a major autoantigen, the enzyme glutamic acid decarboxylase (GAD). GAD is located in the $\beta$ cells of the pancreas and in the GABA producing neurons of the peripheral nervous system and $\mathrm{CNS}^{7}$ In stiff-man syndrome, high GAD antibody (GADA) titres are characteristic and, although controversial, these have been suggested to cause functional impairment of the GABA mediated physiological process, thereby explaining the neurological symptoms. In accordance with this, treatment of patients by plasmapheresis and/or immunosuppressive agents such as prednisolone result in an improvement of neurological symptoms. ${ }^{8}$ However, no studies so far exist on the course of humoral and cellular immune markers during immune intervention therapy.

GADA recognises several epitopes within the GAD65 molecule, including two relatively stiff-man syndrome specific epitopes contained within the carboxy and amino terminal regions. ${ }^{9}$ Antibodies to other pancreatic islet proteins including insulin and the protein tyrosine phosphatase-like molecule IA-2 are also found in patients with insulin dependent diabetes mellitus. IA-2 antibodies (IA-2A) can be detected in a minority of patients with stiffman syndrome, most, ${ }^{10}$ but not all ${ }^{11}$ having insulin dependent diabetes mellitus. $\beta$ Cell death and decline of insulin release in insulin dependent diabetes mellitus are not considered to be causally related to antibodies, including GADA, but are more likely to be $\mathrm{T}$ cell mediated. T Cell proliferative responses to GAD65 and other islet autoantigens can be found in patients with insulin dependent diabetes mellitus, ${ }^{12}$ but as yet there have been no reports of cellular immunity to GAD in stiff-man syndrome.

To determine whether neurological symptoms in stiff-man syndrome are directly related to autoimmunity we investigated both humoral (antibodies) and cellular immune responses ( $\mathrm{T}$ cell proliferation and cytokine release) to GAD65 and IA-2, in a patient with stiff-man 
syndrome and insulin dependent diabetes mellitus before and during immunosuppressive therapy with prednisolone.

\section{Objectives and methods \\ PATIENT}

Stiff-man syndrome was diagnosed in 1994 in a 51 year old man. He fulfilled all criteria established by Lorish et $\mathrm{al}^{13}$ as (1) prodome of rigidity and stiffness in axial muscles, (2) progression of rigidity and stiffness to include proximal limb muscles, (3) deforming of the spine, in this case lordosis, (4) superimposed spasms precipitated by sudden movement and noise, (5) normal muscle strength and sensory examination, (6) normal intellect, (7) the classic EMG findings (continuous normal motor unit firing, despite the patient's intention to relax), and (8) a favourable response to oral administration of diazepam. One year after the diagnosis of stiff-man syndrome the patient had an overtly diabetic glucose tolerance test and was diagnosed as having insulin dependent diabetes mellitus. Partial strumectomy had been performed in 1984, but today it is not possible to determine whether the hyperthyroidism was caused by Graves' disease or by an adenoma of the thyroid gland. A kidney biopsy performed because of recurrent microhaematuria disclosed the rare syndrome of "thin basal membranes $(200 \mathrm{~nm})$ ". This is the first description of a patient with stiff-man syndrome with this extremely rare nephropathy.

The patient had GAD antibodies and islet cell antibodies, but no other organ specific or non-organ specific antibodies. Cell count and protein content in the CSF were normal without oligoclonal bands. GAD antibodies were not measured in CSF samples. The HLA type of the patient is HLA-A1,23; B8,50; DR3,3; DQA $1{ }^{\star} 0501,0501 ;$ DQB ${ }^{\star} 0201,0201$.

IMMUNOSUPPRESSIVE THERAPY

The patient was first treated with diazepam $(3 \times 2.5-5 \mathrm{mg} /$ day $)$ for one year. Diazepam was then no longer effective and the treatment was changed to baclofen ( $3 \times 20-25 \mathrm{mg} /$ day), also a GABAergic agonist. Clinical improvement was seen, but lasted only four weeks. Immunosuppressive therapy was therefore initiated, starting with $500 \mathrm{mg}$ intravenous prednisolone from day 1 to 10 , followed by oral administration and decreasing doses of 80 to $5 \mathrm{mg}$. Currently, after 400 days of therapy the patient has good mobility and is without rigidity with $5 \mathrm{mg}$ prednisolone and $3 \times 5 \mathrm{mg}$ diazepam daily (figure $\mathrm{A}$ and $\mathrm{B}$ ). An oral glucose tolerance test (OGTT) performed before immunosuppression, was clearly abnormal $(0 \mathrm{~min} 170 \mathrm{mg} \%$, $120 \mathrm{~min} 215 \mathrm{mg} \%, \mathrm{HbA}_{\mathrm{c}} 7.2 \%$ ) compared with the OGTT of one year before, which indicated impaired glucose tolerance, but no overt diabetes (0 min $119 \mathrm{mg} \%, 120 \mathrm{~min} 190 \mathrm{mg} \%$, $\mathrm{HbAl}_{\mathrm{c}} 5.8 \%$ ), and insulin therapy was started in parallel with the corticosteroid treatment.

Serum samples for detection of antibodies and venous blood for isolation of peripheral blood lymphocytes for $\mathrm{T}$ cell proliferation assay were isolated at day-180 before immunosuppressive therapy and at day $0,5,10,20,30,50$,
100, and 201 of the therapy. Blood samples were obtained in the morning before administration of steroid medication. Assays were performed blinded without knowledge of the clinical status of the patient.

AUTOANTIBODIES TO GAD, GAD EPITOPES, IA-2, IAA, AND ICA

Antibodies to GAD (GADA) and IA-2 (IA-2A) were analysed by radioligand binding assays as previously described. ${ }^{14}$ Serum samples were tested for IAA using a competitive fluid phase radiobinding assay and expressed in $\mathrm{nU} / \mathrm{ml}$ insulin precipitated. ${ }^{15}$ The threshold of positivity for GADA (13 U), IA-2A (5 U), and IAA (49 $\mathrm{nU} / \mathrm{ml}$ ) were defined as the 99 th percentile of antibody concentrations in a control reference population. Undiluted serum samples were screened for conventional ICA-IgG by means of indirect immunofluorescence ${ }^{15}$ and titres expressed in Juvenile Diabetes Foundation units (JDF U, threshold 5 JDF U). To detect GAD antibodies reactive with epitopes contained within the amino terminal, middle, and carboxy terminal regions of GAD65, GAD65/GAD67 chimeric constructs and GAD65 deletion constructs similar to those previously described ${ }^{1617}$ were prepared. Human GAD65 and GAD67 cDNAs in the pGEM3 vector ${ }^{18}$ were used as the source for the chimeric constructs. GAD65 ${ }_{1-94} / \mathrm{GAD} 7_{101-593}$,

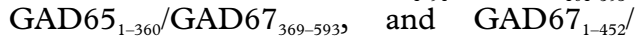
GAD 65 ${ }_{444-585}$ chimeric constructs and the deletion constructs GAD6 $5_{233-585}$, GAD65 ${ }_{290-585}$, and GAD $65_{290-511}$ were used. All constructs were under the control of the SP6 promotor. Antibody binding to in vitro transcribed and translated ${ }^{35} \mathrm{~S}$-labelled proteins was measured as previously described. ${ }^{19}$ Results were expressed as an antibody index relative to a serum from a patient with stiff-man syndrome with high titre GADAs.

T CELL STIMULATION TEST AND CYTOKINE DETERMINATION

Blood samples were analysed for Tcell reactivity to GAD and IA-2 as previously described. ${ }^{20}$ To exclude interassay variability during follow up, lymphocytes before and after therapy from all patient visits were frozen and, after completion of the study, tested in one $\mathrm{T}$ cell proliferation assay. Cells were frozen in 50\% FKS and $10 \%$ dimethylsulphoxide (DMSO) and stored for 48 hours at $-80^{\circ} \mathrm{C}$ and afterwards in liquid nitrogen. By using this standardised freezing protocol in previous experiments we did not find significant differences between fresh and frozen cells for $T$ cell reactivity to GAD and IA-2 (data not shown). Results were expressed as $\mathrm{SI}(\mathrm{SI}=\mathrm{cpm}$ peripheral blood lymphocytes in the presence of antigen/cpm peripheral blood lymphocytes in medium alone). All antigens were tested in triplicate. Recombinant GAD65 was produced in a baculovirus system, purified by immobilised metal affinity chromatography on a chelate sepharose column (Elias, Freiburg, Germany), and tested in concentrations of $0.25,0.5,2.5$, and $5 \mu \mathrm{g} / \mathrm{ml}$. The intracellular domain of tyrosine phosphatase IA-2 was produced as a biotin labelled protein 
from clone IA-2ic (residues 603-980 ${ }^{21}$ ), which was provided to us by M Christie (Department of Medicine, King's College of Medicine and Dentistry, London, UK). After purification, the proteins were used at a concentration of $0.1,1$, 5 , and $10 \mu \mathrm{g} / \mathrm{ml}$. GAD65 and IA-2 did not contain significant concentrations of endotoxin (GAD65 < $0.06 \mathrm{EU} / \mathrm{ml}$, IA-2 <0.06, medium $<0.06 \mathrm{EU} / \mathrm{ml}$ ). Furthermore, in previous studies ${ }^{12}{ }^{20}$ we did not detect significant differences between stimulation indices of GAD65 and IA-2 in normal controls suggesting that potential Escherichia coli contaminations of IA-2 had no major effect themselves on $\mathrm{T}$ cell stimulation compared with the baculovirus product GAD65. As a positive control, tetanus toxoid (Boehringer, Germany; $0.015 \mathrm{U} / \mathrm{ml}$ ) and phytohaemagglutinin (PHA) (Difco, Detroit, Michigan; 0.05\%) was used. The nuclear antigen La (Elias, Freiburg, Germany; $1 \mu \mathrm{g} / \mathrm{ml}$ ) produced in a baculovirus system and purified the same way as GAD65 was included in each assay. Cytokine supernatants were generated by the $\mathrm{T}$ cell stimulation test described above
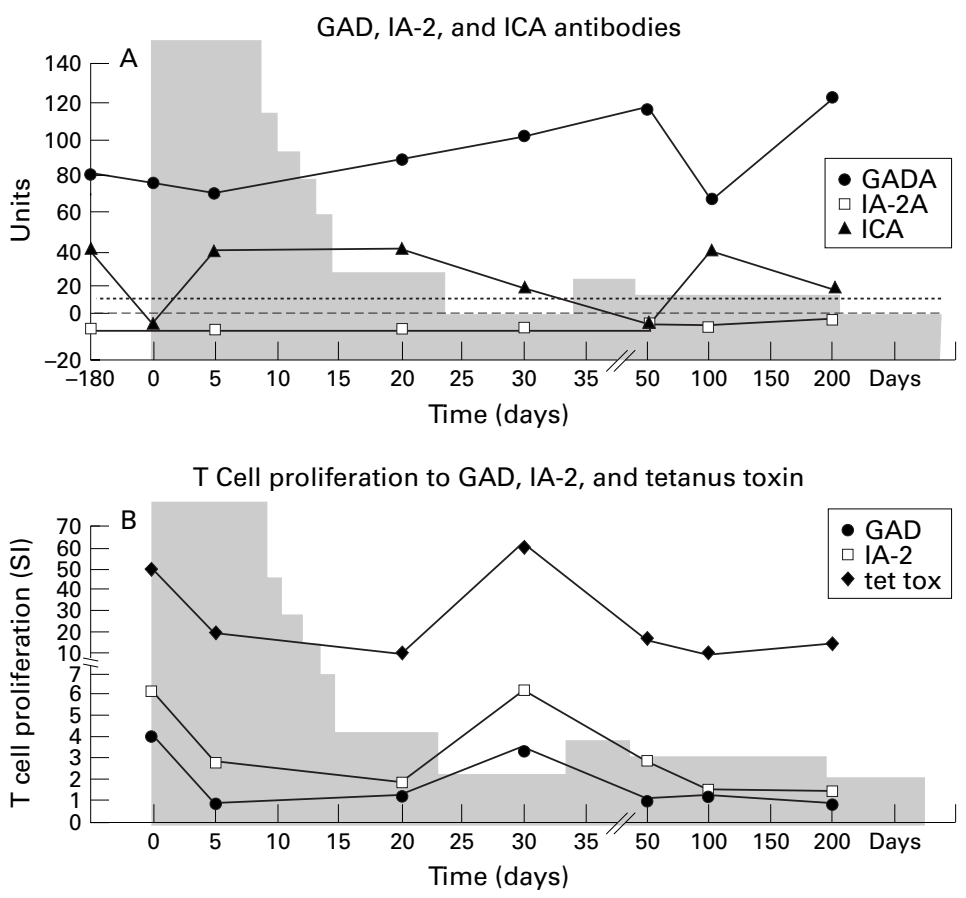

\begin{tabular}{|c|c|c|c|c|c|c|}
\hline \\
\hline & & \multicolumn{5}{|c|}{ Clinical status } \\
\hline $\begin{array}{l}\text { Immobile } \\
\text { rigid } \\
\text { stiff }\end{array}$ & & $\begin{array}{r}\text { No ric } \\
\text { an } \\
\text { no stif }\end{array}$ & & Relapse & & $\begin{array}{l}\text { No rigidity and } \\
\text { no stiffness }\end{array}$ \\
\hline \multicolumn{7}{|c|}{$\begin{array}{l}\text { Prednisolone } \\
\text { (mg/day) }\end{array}$} \\
\hline 0 & $\begin{array}{l}500 \\
\text { (iv) }\end{array}$ & $\begin{array}{c}80 / 60 / \\
40 / 20 \\
\text { (oral) }\end{array}$ & 10 & 5 & 10 & $10 / 7.5^{*}$ \\
\hline
\end{tabular}

(A) Course of GAD, IA-2, and ICA antibody concentrations before and during immunsuppressive therapy ( $x$ axis shows the days from the first treatment with cortisone $=$ day 0 (grey columns indicate the cortisone dosage)). GADA titres were raised (cut off $13 U$, upper broken line) before cortisone treatment and persisted during the therapy. IA-2A were negative in all samples (cut off $5 \mathrm{U}$, lower broken line). ICA fluctuated during treatment (cut off $57 D F-U$ ). No relation between antibody titres and clinical status as well as

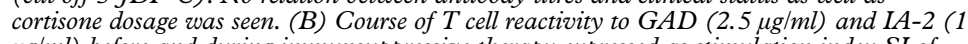
$\mu \mathrm{g} / \mathrm{ml}$ ) before and during immunsuppressive therapy expressed as stimulation index SI of peripheral blood lymphocyte responses (y axis). Raised SIs were found before therapy and under reduction of prednisolone to $5 \mathrm{mg}$. $* 3 \times 5 \mathrm{mg}$ diazepam/day was administered in addition to cortisone. and $100 \mu \mathrm{l}$ supernatants were harvested after 72 hours and tested for IFN- $\gamma$ with commercial enzyme linked immunosorbent assay (ELISA) kits (Laboserv, Giessen, Germany). The detection range was $4-1000 \mathrm{pg} / \mathrm{ml}$ for IFN- $\gamma$.

\section{Results}

PATIENT

Immunosuppressive therapy was initiated after diazepam and baclofen mono-therapy had lost effect. The first dose of prednisolone $(2 \times 250$ $\mathrm{mg}$ daily) injected intravenously led to a complete disappearance of previously described symptoms within 3-4 hours. After 10 days the therapy was changed to oral medication and the doses were successively decreased to $5 \mathrm{mg} /$ day. On day 30 of therapy the patient relapsed with rigidity and stiffness. The prednisolone dose was increased to $10 \mathrm{mg}$ with additional $3 \times 5 \mathrm{mg}$ of diazepam/day. On day 201 prednisolone was reduced to $5 \mathrm{mg}$ /day together with $3 \times 5 \mathrm{mg}$ diazepam. His condition improved and on day 400 he had good mobility and much less muscle rigidity and stiffness than before the therapy.

\section{ANTIBODIES}

At diagnosis the patient had raised concentrations of GADA. Raised antibody concentrations were found against the GAD65 ${ }_{1-94} / \mathrm{GAD} 67_{101-593}$ (amino terminal epitope), GAD65 ${ }_{1-360}$ / $\mathrm{GAD}_{369-593}$, and GAD67 ${ }_{1-452} / \mathrm{GAD} 5_{444-585}$ (carboxy terminal epitope) chimeric constructs, but not the deletion constructs. During the course of immunosuppressive therapy no change in GADA titres against full length GAD65 (figure A) or chimeric constructs were found and no relation between circulating GADA titres and clinical patterns was seen (figure $\mathrm{A}$ and $\mathrm{B}$ ). The patient also had ICAs and IAAs. The ICAs fluctuated and were not detectable before immunosuppression and in one sample during the course of immunotherapy. The IAAs increased after insulin dependent diabetes mellitus diagnosis and exogenous insulin therapy. IA-2As were undetectable in all samples (figure $\mathrm{A}$ ).

\section{T CELL STIMULATION TEST AND CYTOKINE} CONCENTRATIONS

Before immunosuppressive therapy $\mathrm{T}$ cells responded to GAD65 (SI=4) and IA-2 $(\mathrm{SI}=6.2$ ) (figure $\mathrm{B}$ ). High dose steroid medication resulted in decreased cellular reactivity to GAD and IA-2 together with clinical improvement of the patient. On day 30 (reduction of prednisolone therapy to 5 $\mathrm{mg} /$ day) rigidity and stiffness returned followed by increased $\mathrm{T}$ cell responses to GAD65 and IA-2 $\left(\mathrm{SI}_{\mathrm{GAD}}=3.4\right.$ and $\mathrm{SI}_{\mathrm{IA}-2}=6.2$, respectively). A subsequent increase in steroid therapy $(10 \mathrm{mg} /$ day $)$ which resulted in improved mobility was accompanied by a persistent decrease in cellular reactivity to GAD65 and IA-2. T cell reactivity to the control antigens, tetanus toxoid, and PHA was also influenced by immunosuppressive therapy (as shown for tetanus in figure B). On day 30 when steroid therapy was reduced and clinical symptoms returned, a sixfold increase of $\mathrm{T}$ cell 
reactivity to tetanus toxoid (figure $\mathrm{B}$ ) and a threefold increase in proliferation to PHA (data not shown) were seen. The concentrations of IFN- $\gamma$ as a marker of $T_{H} 1$ dominated $T$ cell response, were measured in supernatants of $\mathrm{T}$ cell stimulation tests. At initiation of immunosuppressive therapy and on day 30 (remission of stiff-man syndrome symptoms) high concentrations of IFN- $\gamma$ were detected in response to both antigens; $\mathrm{T}$ cells incubated with GAD65 secreted 183 and $175 \mathrm{pg} / \mathrm{ml}$ respectively and T cells incubated with IA-2 secreted considerably higher IFN- $\gamma$ concentrationsnamely, $>1000 \mathrm{pg} / \mathrm{ml}$. At all time points $\mathrm{T}$ cell responses directed against either GAD65 or IA-2 were accompanied with high IFN- $\gamma$ concentrations. Cytokine concentrations to both antigens were dependent on antigen concentrations.

\section{Discussion and conclusions}

The aetiology and pathogenic mechanisms leading to stiff-man syndrome are still unknown. Antibodies to glutamic acid decarboxylase which are usually found in extremely high titres in such patients (10-1000-fold higher than titres found in insulin dependent diabetes mellitus without stiff-man syndrome) have been discussed as being causally responsible for the neurological disorder. In addition, nonspecific inflammatory reactions and $T$ cells have also been suggested as being involved..$^{22}$ We report a patient with classic clinical symptoms of stiff-man syndrome and relatively high titres of GADAs. ${ }^{24}$ Despite clinical improvement, circulating GADA titres against full length GAD65 or GAD65/GAD67 chimeric constructs were stable during immunosuppression with corticosteroids. This indicates that immunotherapy had neither an effect on the concentration of circulating antibodies nor on the epitope binding characteristics of antibodies. Similar findings have been reported for several other autoimmune disorders in which antibody concentrations show no correlation with clinical symptoms. ${ }^{25}$

By contrast with the high concentrations of GADAs, $T$ cell responses to GAD were low. In addition, raised $T$ cell reactivity was found not only after stimulation with GAD, but also with the insulin dependent diabetes mellitus related autoantigen IA-2. Despite this, $\mathrm{T}$ cell proliferation itself was more closely related to neurological symptoms than antibody concentrations . T cell reactivity, including that against control antigens, correlated with the corticosteroid therapy and the clinical status of the patient, showing the highest reactivity before steroid treatment and during reduced doses of steroids at day 30 when the patient relapsed and showed clinical deterioration. This is in agreement with the reported finding that corticosteroids inhibit $\mathrm{T}$ cell proliferation and cytokine production in antigen stimulated $\mathrm{T}$ cells $^{26}$ and with previous findings describing parallel changes of $T$ cell reactivity and a clinical score in three of six patients with myasthenia gravis treated with immunesuppressive therapy (azathioprine).$^{27} \mathrm{~A}$ modulation of synaptic transmission by corticosteroids is another possible mechanism by which the rapid clinical improvement may be explained. Such effects have not been reproducibly shown for corticosteroids, but agonistic as well as antagonistic effects of neurosteroids have been found at the $\mathrm{GABA}_{\mathrm{A}}$-receptor, ${ }^{28}$ and therefore such a mechanism cannot be excluded.

In summary, we conclude and confirm that high doses of steroids - despite having no effect on antibody titres-induce remission in patients with stiff-man syndrome which can be sustained under low dose therapy for more than one year. A general increase of $\mathrm{T}$ cell reactivity to various antigens was found before immunotherapy and once on withdrawal of high cortisone dosages. Although increased T cell reactivity was not specific for GAD it showed an intriguing correlation with clinical symptoms. Sstudies on T cell proliferation may therefore become a useful marker to monitor immunosuppression.

We thank Professor E Albert (Laboratory of Immunogenetics, University Munich, Germany) for HLA typing and U Mollenhauer, S Seggewi $\beta$, and J Vordemann for technical assistance. This study was supported by grants of the Deutsche Forschungsgemeinschaft DFG (Zi 310/5-4).

1 Toro C, Jacobowitz DM, Hallett M. Stiff-man syndrome. Semin Neurol 1994;14:154-8.

2 Sander JE, Layzer RB, Goldsobel AB. Congenital stiff-man syndrome. Ann Neurol 1980;8:195-7.

3 Folli F, Solimena M, Cofiell R, et al. Autoantibodies to a $128-\mathrm{kDa}$ synaptic protein in three women with the stiff-man syndrome and breast cancer. N Engl f Med 1993; 328:546-51

4 De Camilli P, Thomas A, Cofiell R, et al. The synaptic vesicle-associated protein amphiphysin is the $128-\mathrm{kD}$ autoantigen of stiff-man syndrome with breast cancer. $\mathcal{F}$ Exp Med 1993;178:2219-23.

5 Layzer RB. Stiff-man syndrome-an autoimmune disease? N Engl f Med 1988;318:1060-1.

6 Solimena M, Folli F, Aparisi R, et al. Autoantibodies to GABA-ergic neurones and pancreatic beta cells in stiff-man syndrome. N Engl F Med 1990;322:1555-60.

7 Baekkeskov S, Aanstoot HJ, Christgau S, et al. Identification of the $64 \mathrm{k}$ autoantigen in insulin-dependent diabetes as the GABA-synthesizing enzyme glutamatic acid decarboxylase. Nature 1990;347:151-6.

8 Vicari AM, Folli F, Pozza G, et al. Plasmapheresis in the Vicari AM, Folli F, Pozza G, et al. Plasmapheresis in the
treatment of stiff-man syndrome. $N$ Engl F Med 1989;320: treatm 1499 .

9 Butler MH, Solimena M, Dirkx R Jr, et al. Identification of a dominant epitope of glutamatic acid decarboxylase GAD65) recognized by autoantibodies in stiff-man syndrome. F Exp Med 1993;178:2097-106.

10 Christie MR, Genovese S, Cassidy D, et al. Antibodies to islet $37 \mathrm{k}$ antigen, but not to glutamate decarboxylase, discriminate rapid progression to IDDM in endocrine autoimmunity. Diabetes 1994;43:1254-9.

1 Martino G, Grimaldi GM, Bazzigaluppi E, et al. The insulin-dependent diabetes mellitus-associated ICA 105 autoantigen in stiff-man syndrome patients. $\mathcal{F}$ Neuroimmunol 1996;69:129-34.

12 Hummel M, Durinovic-Bello I, Ziegler AG. Relation between cellular and humoral immune response to diverse islet-cell antigens in IDDM. F Autoimmun 1996;9:427-30.

13 Lorish TR, Thorsteinsson G, Howard FM. Stiff-man syndrome updated. Mayo Clin Proc 1989;74:729-37.

14 Roll U, Christie MR, Füchtenbusch M, et al. Perinatal autoimmunity in offspring of diabetic parents. The German multicenter BABY-DIAB study: detection of humoral immune response to islet antigens in early humoral immune response to islet
childhood. Diabetes 1996;45:926-33.

15 Ziegler AG, Ziegler R, Vardi P, et al. Lifetable analysis of progression to diabetes of anti-insulin autoantibody positive relatives of individuals with type 1 diabetes. Diabetes 1989;38:1320-5.

16 Falorni A, Ackefors M, Carlberg C, et al. Diagnostic sensitivity of immunodominant epitopes of glutamatic acid
decarboxylase (GAD65) autoantibodies in childhood IDDM. Diabetologia 1996;39:1091-8.

17 Nemni R, Braghi S, Natali-Sora MG, et al. Autoantibodies to glutamatic acid decarboxylase in palatal myoclonus and epilepsy. Ann Neurol 1994;36:665-7.

18 Bonifacio E, Genovese S, Braghi S, et al. Isle T autoantibody markers in IDDM: risk assessment strategies yielding high markers in IDDM: risk assessment strategito

19 Bonifacio E, Lamposona V, Genovese S, et al. Identification of protein tyrosine phosphatase-like IA2 (isleT-cell antigen 512 ) as the insulin-dependent diabetes-related $37 / 40 \mathrm{~K}$ 
autoantigen and a target of isleT-cell antibodies. F Immunol 1995:155:5419-26.

20 Durinovic-Bello I, Hummel M, Ziegler AG. Cellular immune response to diverse isle T-cell antigens in IDDM. Diabetes 1996;45:795-800.

21 Payton MA, Hawkes CJ, Christie MR. Relationship of the $37000-$ and $40000-M_{\mathrm{r}}$ tryptic fragments of islet antigens in insulin-dependent diabetes to the protein tyrosine phosphatase-like molecule IA-2 (ICA512). $\mathcal{f}$ Clin Invest 1995;96:1506-11,

22 Piccolo G, Cosi V, Zandrini C, et al. Steroid-responsive and dependent stiff-man syndrome: a clinical and electrophysiologic study in two cases. Ital 7 Neurol Sci 1988;9:559-77.

23 Harding AE, Thompson PD, Kocen RS, et al. Plasma exchange and immunosuppression in the sifff-man syndrome. Lancet 1989;ii:915.
24 Ellis TM, Atkinson MA. The clinical significance of an autoimmune response against glutamic acid decarboxylase. autoimmune response ag in

25 Naparstek Y, Plotz PH. The role of autoantibodies in autoimmune diseases. Ann Rev Immunol 1993;11:79-104. 26 Brinkmann V, Kristofic C. Regulation by corticosteroids of Th1 and Th2 cytokine production in human CD4+ effector $\mathrm{T}$ cells generated from CD45RO- and CD45RO+ subsets. F Immunol 1995;155:3322-8.

27 Hohlfeld R, Toyka KV, Besinger UA, et al. Myasthenia gravis: reactivation of clinical disease and of autoimmune factors after discontinuation of long-term azathioprine. Ann Neurol 1985;17:238-42.

28 Mellon SH. Neurosteroids: biochemistry, modes of action, and clinical relevance. $\mathcal{F}$ Clin Endocrinol Metab 1994;78: $1003-8$.

\section{NEUROLOGICAL PICTURE}

\section{Pontine inflammatory lesion due to shingles}

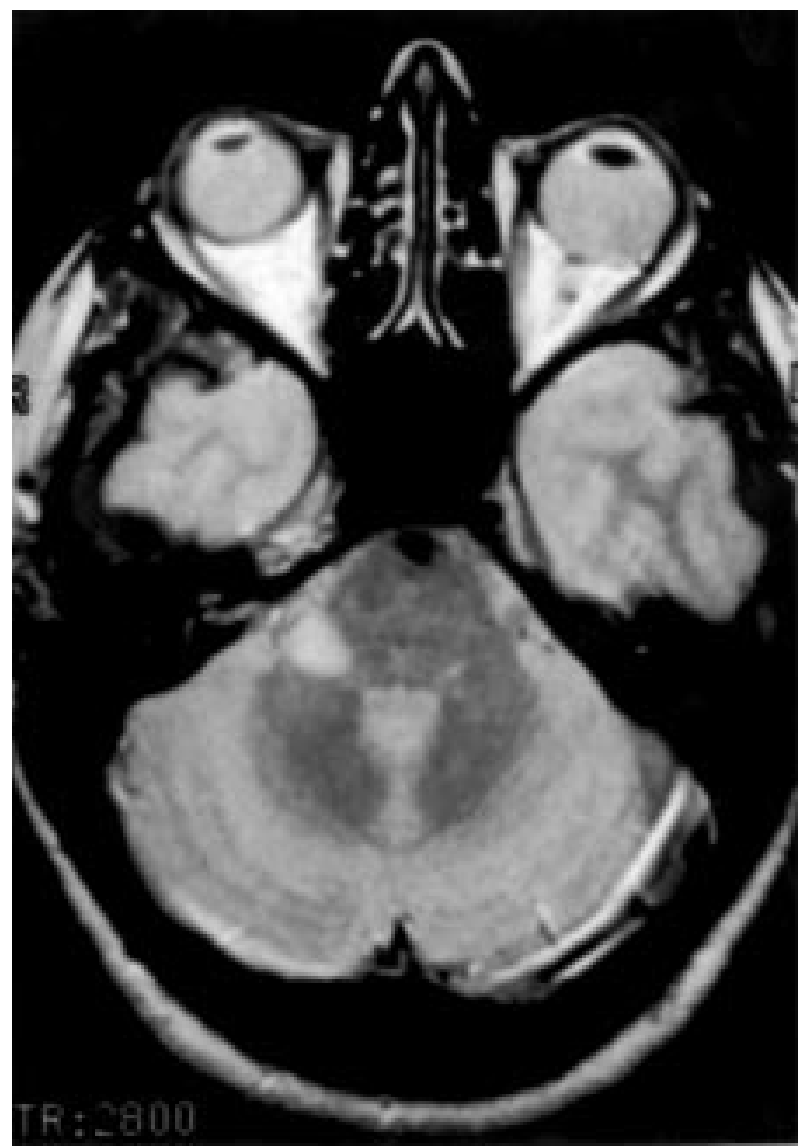

$T_{2}$ weighted MRI (TR $2800 \mathrm{~ms}$, TE $92 \mathrm{~ms}$ ) at $0.5 T$ showing a single lesion in the right pons at the origin of the right middle cerebellar peduncle.
A 61 year old woman developed tingling at the corner of the right side of her mouth which spread over the next week to involve the whole of the right side of her face. The symptoms were static for two weeks, then gradually receded over the next four weeks. There were no associated neurological symptoms. Simultaneous with this she developed a painful vesicular rash over the right side of the face.

Neurological examination showed a right trigeminal sensory neuropathy and no other signs.

Brain MRI showed an area of high signal in the right pons, and no other lesions elsewhere.

$\mathrm{CSF}$ protein was raised at $0.75 \mathrm{~g} / \mathrm{l}$ but the CSF was acellular. Oligoclonal bands were present in the CSF but absent in serum. The CSF IgG showed high affinity binding to Varicella zoster antigen. This strongly suggests that the pathogenesis of the brainstem lesion was directly related to the preceding episode of shingles.

At follow up four months later she had made a complete recovery.

D KIDD

J S DUNCAN

E J THOMPSON

Departments of Clinical Neurology and Neuroimmunology, The National Hospital for Neurology and Neurosurgery,

Queen Square, London WC1N $3 B G$, UK 